with severe hookworm anaemia (Hb 3 g. $/ 100 \mathrm{ml}$., hookworm load of 1,020 worms) to oral ferrous sulphate and Imferon (T.D.I.). He responded well to deworming with tetrachlorodiphenyl-ethane (T.C.E.) and ferrous sulphate, which he had for five months. However, seven months later he was admitted with recurrence of severe hookworm anaemia (Hb $3.6 \mathrm{~g} . / 100 \mathrm{ml}$. and hookworm load of 860 worms). This time he was treated with T.C.E. and total dose Imferon, to which he made a good response. The haemoglobin reached normal level within three months. He was followed for 10 months after the therapy. During this period he became reinfected with hookworm, but his haemoglobin remained consistently high.

There were no general reactions at the time of Imferon infusion. Five patients, however, had thrombophlebitis at the site of infusion, and two developed fever two days and three days respectively after the infusion.

\section{Discussion}

The total dose Imferon infusion technique provides a safe, convenient, and rapidly effective means of replenishing the patient's body iron (Marchasin and Wallerstein, 1964). It must be stressed, however, that severe systemic reactions may occur, and this treatment should always be carried out with due caution. Oral iron therapy would take many months to be effective, and it is very difficult to supervise in outpatients. The haematological response was better with Imferon. However, with both forms of iron therapy the lower the initial haemoglobin level the more rapid and dramatic the response. It was most marked during the first two weeks after infusion therapy. When the single infusion is completed there is absolute certainty that the patient has received the precise amount of iron required for the complete restoration of haemo- globin, body iron reserves, and tissue iron. The follow-up study has shown that because of this the patients treated with Imferon did not become anaemic even though they became reinfected with hookworm. The patients preferred to have their treatment in one day, and therefore showed a preference for total dose Imferon infusion therapy.

\section{Summary}

The response of 45 patients with severe hookworm anaemia to total dose Imferon infusion was compared with that of 15 patients given oral ferrous sulphate. Recovery after Imferon was more rapid. Abnormal reactions to Imferon were infrequent and mild. Follow-up studies showed that reinfection with hookworm was extremely common. Patients treated 'with ferrous sulphate quickly relapsed into severe anaemia when infection with hookworm recurred. This was in marked contrast with the Imferon-treated group, whose haemoglobin levels still remained uniformly high. This must be attributed to the replacement of the iron reserves by total dose Imferon, and is one of the main advantages of using this technique in anaemias occurring in the tropics.

We are grateful to our colleagues for allowing us access to their patients, and to Dr. G. D. Ballantyne, of Fison Pharmaceuticals Ltd., England, for providing Imferon.

\section{REFERENCES}

Marchasin, S., and Wallerstein, R. O. (1964). Blood, 23, 354.

Meredith, J. S., and Eyekuze, V. M. (1962). E. Afr. med. F., 39, 250. Pritchard, J. A., and Mason, R. A. (1964). F. Amer. med. Ass., 190, 897. Varde, K. N. (1964). F. Obstet. Gynaec. Brit. Cwith, 71, 919. Wilks, N. E., and Patel, K. M. (1967). To be published.

\title{
Choledochoduodenostomy in Treatment of Chronic Pancreatitis and Choledocholithiasis
}

\author{
J. N. BURGESS,* M.B., B.S., F.R.C.S. ; H. A. KIDD, † F.R.C.S., F.R.C.S.ED.
}

Brit. med. F., 1967, 2, 607-609

Choledochoduodenostomy is not often performed in this country. We feel that it has a valuable part to play in the treatment of chronic relapsing pancreatitis, and that it is the procedure of choice in choledocholithiasis. Our purpose here is to show that this neglected operation is neither difficult nor dangerous, and should be much more widely used. It has suffered from the somewhat theoretical objections that such an anastomosis is difficult to perform, that it would predispose to ascending cholangitis, and that stricture of the common bile duct above the anastomosis would occur in a high proportion of patients owing to reflux of duodenal contents. We hope that this paper will help to dispel these doubts and give the procedure its rightful place among surgical techniques.

\section{Indications}

We feel that the indications for performing this operation are as follows:

1. Chronic pancreatitis, either diagnosed preoperatively and confirmed at operation or encountered at operation. The condition may be either pancreatitis alone or pancreatitis associated with calculous disease of the biliary tract.

* Researci Assistant, Mayo Clinic, Rochester, Minnesota. t Consultant Surgeon, St. Helier Hospital, Carshalton, Surrey.
2. Choledocholithiasis: the stones in the common bile duct may be associated with stones in the gall bladder, in which case cholecystectomy should also be performed. The patient may previously have undergone cholecystectomy with or without exploration of the common bile duct for calculous disease.

We have also used this procedure for palliation in cases of irremovable carcinoma of the head of the pancreas, but these cases do not constitute any part of the series here presented.

\section{Present Series}

This series comprised 31 patients treated in a busy general surgical unit by choledochoduodenostomy in the 10-year period from 1 June 1956 to 1 June 1966. No patient was refused operation because of advanced age or general debility, and the operations were performed by one of us (H. A. K.) or his senior registrar.

Twenty-seven patients were followed up by personal interview by one of us (J.N.B.) ; three were over 85 years of age and were seen by their own general practitioners as it was not thought justifiable to bring these very old people to hospital, and one was in a mental hospital and was interviewed by his psychiatrist. All were asked if they were satisfied with the result of the operation and if they ever suffered abdominal pain or indigestion since it was completed. They were specifically 
asked if they had ever been jaundiced, whether their bowel actions were normal, or if they had had attacks of diarrhoea at any time. Inquiries were made whether they had lost any weight and whether their appetite was normal. Finally, they were all asked if they ever suffered pain after taking fizzy drinks, as we had a clinical impression that some of these patients had right hypochondrial pain when intestinal gas distended the common bile duct.

The ages of the patients varied from 34 to 86 at the time of their operation, with an average of 62 years. The length of follow-up varied from one month to ten years, and averaged four years.

\section{Technique of Operation}

The abdomen was explored through a right upper paramedian incision. The gall bladder, if present, was palpated for the presence of stones, as was the common bile duct. A note was made of the colour, size, and thickness of the common bile duct, and the pancreas was palpated for the presence or absence of pancreatitis.

The peritoneum lateral to the second part of the duodenum was incised and the duodenum and head of the pancreas were thereby mobilized. The head of the pancreas could then be accurately palpated between finger and thumb and a final diagnosis made.

Cholecystectomy was then performed in the usual manner and the common bile duct was incised transversely approximately $2 \mathrm{~cm}$. from the duodenum. If stones were suspected the common bile duct was thoroughly explored through this incision. A posterior layer of fine 000 interrupted black silk sutures was inserted, the tough fibrous wall of the bile duct being picked up $0.5 \mathrm{~cm}$. below the incision and the seromuscular wall of the neighbouring duodenum in its longitudinal axis. The duodenum was then incised longitudinally over the same length as the incision in the bile duct, a continuous fine 000 chromic catgut suture being used to anastomose the cut edges of the two incisions. The anastomosis was completed by an anterior layer of interrupted fine black silk sutures.

As the common bile duct was almost always dilated in these cases, the incision in it was made at least $2 \mathrm{~cm}$. long in order to be certain that stenosis of the anastomosis did not occur. In view of this dilatation and the mobilization of the duodenum, which had been performed for diagnostic purposes, anastomosis was technically easy. Indeed, it was no more difficult than a side-to-side anastomosis between two loops of small bowel. In a few cases when the common bile duct was not dilated the duct was divided and the distal end ligated. The proximal duct was then implanted end-to-side into the duodenum.

A tube drain was brought out from the gall-bladder bed and the abdominal incision closed in the routine manner.

\section{Results}

\section{Chronic Pancreatitis}

There were 22 cases in this group; of these, 9 had pure pancreatitis and 13 had pancreatitis complicated by calculous disease of the biliary tract. One patient was an alcoholic, two were diabetics, and none had any evidence of pancreatic stones. The duration of symptoms varied from eight hours to five years, with an average of nine months.

The result was regarded as good if the patient on direct questioning stated that he either had no symptoms whatsoever or had only minimal abdominal pain or discomfort. The result was regarded as poor if the patient had had severe pain, jaundice, or recurrence of stones, or had undergone further hospitalization or surgery.

No operative deaths occurred from any cause in this group, and in $20(91 \%)$ patients the results were thought to be good.
Ten patients had no symptoms whatsoever. Five had occasional slight epigastric discomfort after meals ; this occurred less than once a week, was in no way disabling, and did not even require household remedies for its relief. Two patients had slight heartburn-in one on getting up in the morning and in the other after eating fatty foods-it occurred infrequently, was mild in nature, and lasted only a minute or so. Three patients suffered from right hypochondrial pain. This pain was quite characteristic and was the symptom about which we had a previously held clinical impression. It was described as a sharp jab beneath the right costal margin which lasted about a second and usually occurred only after fizzy drinks had been taken. We believe that this pain is due to gas passing up the common bile duct from the duodenum. If a plain $x$-ray film of the abdomen is taken after giving a patient with a choledochoduodenostomy a fizzy drink (Pepsi-Cola), gas can be detected in the biliary system, and we used this procedure as a test for patency of the anastomosis. It is not known why these three patients should have suffered pain from this cause while none of the others did.

In two $(9 \%)$ patients the results were classified as poor. One was a 66-year-old female diabetic who suffered from attacks of lower abdominal colic which often awakened her at night. She was losing weight and had occasional attacks of diarrhoea. She became jaundiced in April 1964, when she was admitted to hospital ; a further attack of chronic pancreatitis was diagnosed. The other patient was a 34-year-old woman who had had repeated attacks of epigastric pain going through to the back; one of these attacks necessitated her admission to hospital, where a diagnosis of relapsing pancreatitis was made.

Thus 20 out of 22 patients were completely relieved of the symptoms of pancreatitis, and in only two cases did the pancreatitis persist despite choledochoduodenostomy.

There has been no evidence of stricture of the anastomosis or of the common bile duct, and no case of cholangitis.

\section{Choledocholithiasis}

There were nine cases in this group. Four had had a previous cholecystectomy and exploration of the common bile duct. In the other five cholelithiasis was associated with multiple stones in their common ducts.

The operative mortality was nil, but two patients have since died from congestive cardiac failure- one at nine months and one at 20 months after operation. Neither of them had had a recurrence of their calculi nor do their records show that they had any abdominal complaints.

Eight of the nine patients were classified as having good results: three had no symptoms whatsoever; two had slight flatulence after meals-this was infrequent and lasted for only a few minutes; one had some flatulence, and after eating fatty foods occasionally suffered slight griping pain in the right hypochondrium, which was relieved by alkaline mixtures; and the other two were those who died.

One patient was classified as having a poor result. She was a 71-year-old woman who for two years after operation suffered recurrent attacks of epigastric pain. Laparotomy was performed but no abnormality was found. The area of the anastomosis in particular showed no evidence of any disease. This laparotomy dramatically relieved the pain, but she still had a feeling of abdominal distension after food (see Table).

\begin{tabular}{|c|c|c|c|c|c|c|}
\hline \multicolumn{7}{|c|}{ Summary of Results } \\
\hline & & $\begin{array}{l}\text { No. of } \\
\text { Cases }\end{array}$ & $\begin{array}{c}\text { With } \\
\text { Biliary } \\
\text { Calculi }\end{array}$ & $\begin{array}{l}\text { Without } \\
\text { Biliary } \\
\text { Calculi }\end{array}$ & $\begin{array}{l}\text { Good } \\
\text { Result }\end{array}$ & $\begin{array}{c}\text { Poor } \\
\text { Result }\end{array}$ \\
\hline $\begin{array}{l}\text { Chronic pancreatitis } \\
\text { Choledocholithiasis alone }\end{array}$ & 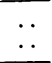 & $\begin{array}{r}22 \\
9\end{array}$ & $\begin{array}{r}13 \\
9\end{array}$ & 9 & $\begin{array}{r}20 \\
8\end{array}$ & 2 \\
\hline Total & $\ldots$ & 31 & 22 & 9 & 28 & 3 \\
\hline
\end{tabular}


Thus overall there were 22 cases of choledocholithiasis- 13 with and 9 without pancreatitis-and none of these had any evidence of recurrent calculi, cholangitis, or stricture.

\section{Discussion}

\section{Chronic Pancreatitis}

The treatment of chronic pancreatitis has not been very satisfactory in the past, as shown by the many different procedures that have been suggested. Indeed, one current surgical textbook lists 13 different methods that can be used (Maingot, 1961).

Chronic relapsing pancreatitis may be caused by reflux of bile up the main pancreatic duct. Doubilet (1957) has shown that in all these cases the common bile duct and the main pancreatic duct join before reaching the ampulla of Vater. He postulated that spasm of the sphincter of Oddi forces bile up the pancreatic duct and that the pain of pancreatitis is due to the chemical inflammation that this causes in the pancreatic acini and to distension of the pancreatic ducts.

Though this explanation has not been universally accepted no other definite cause has been found. It therefore seems rational to treat this condition by preventing this biliary reflux.

Our procedure, of course, short-circuits the bile away from the pancreatic duct, directing it into the duodenum, and reduces the pressure in the pancreatic duct, allowing pancreatic juice to drain via the anastomosis. We think that a Roux-en-Y anastomosis is unnecessarily complicated. Bowers and Greenfield (1951) performed choledochojejunostomy by this method and relieved $76 \%$ of patients ; they described the procedure as a major one and also reported a $7 \%$ stricture rate (Bowers, 1964). Rousselot et al. (1954), however, using this technique, relieved only one patient out of five.

The most commonly used procedure for chronic pancreatitis is probably sphincterotomy of the ampulla of Vater. Doubilet and Mulholland (1956), who are staunch champions of this procedure, obtained $88 \%$ good results with it. Smith (1957), in this country, also performs sphincterotomy, but uses choledochojejunostomy if local induration makes sphincterotomy difficult. However, Warren and Veidenheimer (1962) at the Lahey Clinic obtained only $56 \%$ good results, and Thistlethwaite and Smith (1963) relieved only 7 out of 23 patients.

Even in the hands of an expert this procedure can have a $5 \%$ operative mortality rate (Doubilet and Mulholland, 1956), and Blatherwick and Pattison (1954), reporting three fatal cases of acute pancreatitis after sphincterotomy, advised caution before deciding on this procedure. A theoretical objection to sphincterotomy is that Lempke (1963) has shown that it does not lower the sphincteric resistance in man to any appreciable extent and that, anyway, any effect is transient, being confined to the first week after operation. These results were supported by the findings of Thistlethwaite and Smith (1963).

The other commonly used procedure is lateral anastomosis between the main pancreatic duct and a loop of jejunum (Lempke et al., 1963 ; Silen et al., 1963). This operation, and partial pancreatectomy or pancreaticoduodenectomy, are major procedures that are technically difficult, and we would advise such operations only for patients with pancreatic stones as well as chronic pancreatitis. However, it is important to state that chronic pancreatitis in the United States of America and France seems to be a different clinical entity from that seen in this country. The condition appears to be more severe in that pancreatic stones and alcoholism are more common than in the British series ; indeed, Owens and Howard (1958) described 32 cases of chronic pancreatitis, all the patients being alcoholics.

In our series only one patient was an alcoholic, and though he did well it may be that more extensive procedures are necessary for these patients.

Lempke et al. (1963) and Silen et al. (1963) performed lateral pancreaticojejunostomy for alcoholic chronic pancreatitis, and we would use this same procedure or a distal drainage operation for any patient whose chronic pancreatitis was complicated by pancreatic stones, in order to drain the pancreatic duct. One patient, not in this series, was so treated. She was a girl of 11 years who had had acute pancreatitis in 1949 followed by frequent relapses. In 1955 the tail and part of the body of the pancreas was amputated and Roux-en- $Y$ anastomosis with the jejunum carried out. She has remained well since then.

Capper (1961) reported his series of choledochoduodenostomies in which a similar technique to ours was used. $\mathrm{He}$ found that all nine patients with chronic pancreatitis were completely relieved. We believe, with him, that choledochoduodenostomy is a simple and safe procedure, giving better results than any other method of treatment for non-calculous chronic pancreatitis.

\section{Choledocholithiasis}

In 22 cases of choledocholithiasis with or without chronic pancreatitis treated by side-to-side choledochoduodenostomy we have had no recurrence of stones, no anastomotic strictures, and no cases of cholangitis. We do not believe, however, that choledochoduodenostomy makes exploration of the common bile duct unnecessary. Though biliary mud and gravel can pass through the anastomosis, the common bile duct should be thoroughly explored and any stones removed before the anastomosis is completed.

Hosford (1957) and Capper (1961) in this country and Sanders (1946) and Hurwitz and Degenshein (1964) in America all report no recurrence of calculi after side-to-side choledochoduodenostomy for choledocholithiasis. These results, together with our own findings, confirm our belief that this operation is now the treatment of choice for multiple stones in the common bile duct. We would use transduodenal sphincterotomy only in cases where a stone impacted at the ampulla of Vater cannot be removed from above.

\section{Summary}

A series of 32 patients on whom choledochoduodenostomy by side-to-side anastomosis was performed in the 10-year period $1956-66$ is reported.

The indications for and the technique of operation are described.

Of 22 cases of chronic pancreatitis, 20 were completely relieved of their symptoms.

In 22 cases of choledocholithiasis with or without chronic pancreatitis there was no recurrence of stones.

No patient developed a stricture of the common bile duct or cholangitis.

Choledochoduodenostomy by side-to-side anastomosis is the treatment of choice for chronic relapsing pancreatitis and choledocholithiasis.

\section{REFERENCES}

Blatherwick, N. H., and Pattison, A. C. (1954). Amer. F. Surg., 88, 129 Bowers, R. F. (1964). Ann. Surg., 159, 424. - and Greenfield, J. (1951). Ibid., 134, 99.

Capper, W. M. (1961). Brit. F. Surg., 49, 292.

Doubilet, $\mathrm{H}$ (1957). Proc. roy. Soc. Med., 50, 629.

and Mulholland, J. H. (1956). F. Amer. med. Ass., 160, 521. Hosford, J. (1957). Brit. med. F., 1, 1202.

Hurwitz, A., and Degenshein, G. A. (1964). Surgery, 56, 1147. Lempke, R.' E. (1963). Ann. Surg., 158, 9. King, R. D., and Kaiser, G." C. (1963). Arch. Surg., 87, 90. Maingot, R. (1961). Abdominal Operations, 4th ed. London. Owens, J. L., and Howard, J. M. (1958). Ann. Surg., 147, 326. Rousselot, L. M., Sanchez-Ubeda, R., and Giannelli, S. (1954). New Engl. 7. Med., 250, 267.

Sanders, R. L. (1946). Ann. Surg., 123, 847.

Silen, W., Baldwin, J., and Goldman, L. (1963). Amer. F. Surg., 106, 243

Smith, R. (1957). Proc. roy. Soc. Med., 50, 636.

Thistlethwaite, J. R., and Smith, D. F. (1963). Ann. Surg., 158, 226.

Warren, K. W., and Veidenheimer, M. (1962). New Engl I. Med., 266.
323. 